\title{
Envelhecimento e rejuvenescimento: um estudo de representação social
}

\section{Aging and rejuvenescence: study of social representation}

\section{Resumo}

O estudo baseou-se na teoria das representações sociais para analisar o conteúdo das representações sociais que três gerações diferentes de mulheres têm sobre assuntos relacionados com envelhecimento e rejuvenescimento. Setenta e duas mulheres participaram da pesquisa, sendo 34 universitárias de 25 a 35 anos, 18 de 40 a 50 anos e 20 acima de 60 anos. Utilizou-se como método de coleta e análise de dados a técnica de associação livre de palavras. Os termos indutores foram envelhecimento e rejuvenescimento. A análise dos vocábulos evocados seguiu os critérios de freqüência e de ordem de evocação. Foram calculadas as médias de ambos os critérios para compor os quadrantes que formariam os conteúdos das hipóteses de núcleos centrais e periféricos de representação social. Os principais resultados mostraram que ao redor do envelhecimento ainda existem idéias antigas cristalizadas em imagens, como sabedoria e experiência. Já em relação ao rejuvenescimento, as mulheres participantes expressaram uma atitude favorável à prevenção do envelhecimento direcionada à melhora de condições de saúde, em detrimento dos cuidados estéticos, o que mostra que nos conteúdos centrais está presente uma dimensão funcional da representação social em termos de uma prática de cuidados preventivos. Conclui-se que, independentemente da faixa etária das participantes, elas construíram uma representação social do rejuvenescimento voltada para cuidados em saúde muito mais do que com a beleza estética. Luciana Bosco Donati

Mariana Martinez Facin ${ }^{b}$ Paola Terra Pedreschib

Palavras-chave: envelhecimento; rejuvenescimento; percepção social; mulheres

Correspondência / Correspondence Maria Cristina Trigueiro Veloz Teixeira E-mail: cris@teixeira.org 


\section{Abstract}

This study is based on the theory of the social representations to analyze the content of the social representations that three different generations of women have on subjects related to aging and rejuvenescence. Seventy-two women participated on the research: 34 university students from 25 to 35 years old, 18 from 40 to 50 years old, and 20 above 60 years. The method for data collection and analysis was the technique of free association of words. The inductive terms were aging and rejuvenescence. The analysis of the evoked words followed the criteria of frequency and order of evocation. The averages were calculated in both criteria to create the quadrants that would form the contents of the hypothesis of central and peripheral cores of social representation. The main results had shown that around aging there are still crystallized old ideas in images as wisdom and experience. As to rejuvenescence, the women had expressed a favorable attitude to the prevention of aging directed to the improvement of conditions of health in detriment of the aesthetic cares, showing that in the core contents a functional dimension of the social representation in terms of preventive care practices is present. We concluded that, independently of the participants' age groups, they built a social representation of the rejuvenescence directed toward health care much more than the aesthetic beauty.

Key words: aging; rejuvenation; social perception; women

\section{INTRODUÇÃO}

Segundo dados do IBGE, no final da década de 90 o número de idosos (pessoas com mais de 60 anos) chegou a 14,5 milhões, representando $9,1 \%$ da população brasileira. Estima-se que daqui a 25 anos, aproximadamente, essa população de idosos será superior a 30 milhões $\left(\mathrm{IBGE}^{8}, \mathrm{~s} / \mathrm{d}\right)$. O número de indivíduos idosos vem aumentando devido à elevação da expectativa de vida e também à diminuição dos índices de fecundidade. De um lado aumenta a expectativa de vida e, de outro, nas sociedades em geral acontece um fenômeno social em que o idoso nem sempre é valorizado nos grupos e na família.

Como coloca Morin ${ }^{12}$ (2000), nota-se uma cultura de massa que desagrega os valores gerontocráticos, acentua a desvalorização da velhice, dá forma à promoção dos valores juvenis e assimila uma parte das experiências adolescentes. Cabe ressaltar que, em nível social, mídia, mercado de trabalho e sistemas de produção vendem a imagem de que é o jovem quem produz, trabalha e consome, sendo também voltados para esses jovens os denominados ideais de beleza. Inclusive, muitos indivíduos sentem que a manutenção de uma aparência jovem pode estar associada à vitalidade e produtividade.

Novas crenças e cultos ao corpo se tornam inevitáveis e novos panos de fundo podem determinar pesquisas muito relevantes em psicologia do envelhecimento. Uma das abordagens compreensivas do envelhecimento que tem 
atingido ampla repercussão positiva dentro dos pesquisadores da área gerontológica são as teorias de curso de vida. Citam-se dentro dessa teoria alguns autores de destaque, como Neugarten e Hagestad ${ }^{16}$ (1976) e Baltes ${ }^{2}$ (1987).

Segundo as teorias de curso de vida, o ser humano está em uma progressão contínua de desenvolvimento, desde o nascimento até a morte. Para poder explicar o conceito de envelhecimento, essas perspectivas utilizam a definição de curso de vida. Esses enfoques propõem a definição no seguinte sentido: diversas maneiras como a sociedade atribui significados sociais e pessoais à passagem do tempo biográfico, permitindo a construção social de personalidades e trajetórias de vida, com base em uma seqüência de transições demarcadas socialmente e diferenciadas pela idade.

Baltes $^{2}$ (1987), por exemplo, desenvolveu uma série de pressupostos que, conforme o autor, caracterizariam a teoria. Um deles aponta para uma compreensão de curso de vida como uma resultante dialética da influência de diversos sistemas. Um sistema relaciona-se com a gradação por idade, outro é o contexto histórico, e outros estão compostos pelos sistemas que são associados aos eventos não-normativos. Um evento nãonormativo diz respeito àquele elemento de caráter biológico e ambiental não-universal que dependem da significação individual ou grupal que ele tenha para as pessoas.

Tendo em consideração o pressuposto da teoria de curso de vida proposta por Baltes ${ }^{2}$ (1987), este estudo teve como objetivo geral identificar possíveis representações sociais so- bre dois assuntos de extrema relevância na atualidade, o envelhecimento e o rejuvenescimento, partindo do pressuposto da estreita relação que ambos os conceitos têm ao discutir temas como velhice e juventude. Sobretudo pelo fato de se tratar de assuntos nãonormativos, seguindo a colocação de Baltes acima citada. A pesquisa teve como objetivo específico explorar a saliência de conteúdos centrais de representação social sobre o envelhecimento e rejuvenescimento que grupos de diferentes gerações de mulheres tinham.

As mulheres são os maiores alvos deste novo paradigma que promove a manutenção de uma aparência física jovem cada vez mais prolongada, e isto é trazido pelos meios de comunicação. Jorge ${ }^{11}$ (1999, p. 17) aponta: "[...] Para a mulher a situação parece mais dolorosa, na medida em que a beleza física é o principal atributo de valor para ela no mundo contemporâneo [...]”. Acredita-se que seja por conta dessa exigência que a demanda de mulheres que buscam técnicas de embelezamento tenha aumentado nos últimos anos (Nociti et al. ${ }^{17}$, 2003; Barbosa et al. ${ }^{3}$, 2005). É comum que algumas pessoas confundam muitas dessas abordagens compreensivas sobre o processo de envelhecimento com a definição de rejuvenescimento.

Segundo Stuart-Hamilton ${ }^{23}$ (2002), rejuvenescer é mascarar a velhice e o processo natural de envelhecimento. O rejuvenescimento é um tratamento para atenuar as alterações de envelhecimento. Para isto podem ser usados métodos cirúrgicos, clínicos, cosmetológicos e terapias alternativas naturais para diminuir o envelhecido e tentar obter aparência com ca- 
racterísticas mais parecidas com a dos jovens. A partir de alguns estudos científicos, mostra-se que podem existir benefícios psicológicos com o uso desses métodos, a saber; melhora na autoconfiança, vida profissional e afetiva, e alívio na autopercepção daqueles desconfortos visuais do aspecto externo (Concio \& Rolando 4 , 1977).

Esta pesquisa se baseou na teoria das representações sociais, formulada por Moscovici em Lapsychanalyse, son image et son public (Moscovici ${ }^{13}, 1978$ ), que partiu da tradição sociológica durkheimiana e desenvolveu uma psicossociologia do conhecimento. Esta pressupõe a representação social como um conjunto de conceitos, afirmações e explicações que podem ser considerados como "teorias" do senso comum, que compõem a intersecção entre o que é psicológico e o que é social, e têm por função construir conhecimentos e a comunicação entre os indivíduos. Assim, o objetivo deste trabalho foi analisar a organização e a saliência de conteúdos da representação social de assuntos ligados ao envelhecimento e ao rejuvenescimento em três grupos de mulheres de gerações diferentes.

\section{Envelhecimento, rejuvenescimento $\mathrm{e}$ retardo do envelhecimento}

“Tudo é efêmero e descartável' (Jorge ${ }^{11}, 1999$, p. 14). "É o homem e a mulher que não querem envelhecer, que querem ficar sempre jovens para sempre se amarem e sempre desfrutarem do presente" (Morin ${ }^{12}$, 2000, p. 152). Essas frases exemplificam o surgimento de um novo culto. Culto àquilo que pode ser renovado e se conserva relativamente jovem, o que também está associado ao processo de desvalorização da velhice, visto que, além dos aspectos positivos que a velhice possa ter no sentido de se valorizar como símbolo de autoridade e conhecimento, ela também tem sido vista sob um prisma negativo de doença, inutilidade e conservadorismo (Santos \& Belo $^{21}, 2000$, p. 41).

Para mulher, o processo de envelhecimento nas últimas décadas da vida pode ser sentido com maior afinco, na medida em que seus atributos físicos são fatores relevantes nas competições afetivas e profissionais. Esse envelhecimento pode trazer sentimentos de baixa autoestima e alguns desequilíbrios psicológicos, acarretando uma busca pelo rejuvenescimento. Os métodos de rejuvenescimento são usados para minimizar o impacto do envelhecimento físico em qualquer fase da vida adulta. Atualmente existem inúmeros tratamentos para melhorar os sinais da idade, como a tecnologia da LIP (luz intensa pulsada), que é usada para correção de uma variedade de condições benignas da pele, e a aplicação de Botox, que é um medicamento que relaxa a musculatura onde é aplicado, fazendo com que as marcas de expressão fiquem menos acentuadas.

A procura por alternativas que proporcionam uma aparência mais jovial é muito alta. Dados fornecidos por uma especialista em medicina e responsável pela Clínica Ligia Kogos de Dermatologia, na cidade de São Paulo, confirmam que, em média, são executados por semana 35 a 45 aplicações de Botox em regiões como testa, olhos e pescoço; $30 \mathrm{a}$ 40 preenchimentos no sulco nasolabial, lábios e bochechas com polidimetil ou restylane e, 
10 a 15 aplicações de laser no rosto, mãos, colo, pescoço para a eliminação de manchas e nas pernas para a eliminação de vasos.

A sociedade muitas vezes defende uma crença de que o que é velho também é feio. A juventude tem-se tornado uma espécie de mercadoria, que como qualquer outra pode ser comprada e vendida, e conseqüentemente vem sofrendo uma alteração no seu significado (Schabbel $\left.{ }^{22}, 2002\right)$. Ser jovem tornou-se sinônimo de ser belo, produtivo e eficaz, e talvez por isso a vontade de aparentar-se como tal está sendo assimilada por pessoas de todas as idades.

A medicina se dedica atualmente a não apenas a tratar as pessoas que se encontram enfermas, mas também a cuidar da aparência daquelas que gozam de boa saúde. Existem inúmeras técnicas que podem proporcionar ao indivíduo a possibilidade de sentir-se mais belo ou mais jovem. Segundo a Sociedade Brasileira de Cirurgia Plástica, são realizadas 385 mil cirurgias plásticas no país anualmente, sendo a metade de caráter estético. O Brasil é o segundo país que mais realiza cirurgias plásticas no mundo: a cada três minutos uma pessoa se submete a uma cirurgia plástica $\left(\right.$ COREN $\left.^{18}, 2003\right)$.

A mídia propaga mensagens segundo as quais, para ser feliz, é necessário ser belo, jovem e ter um corpo perfeito, difundindo a idéia de juventude eterna. Alguns indivíduos, receptores dessa ideologia, parecem querer controlar o ciclo de vida inerente a todos os seres vivos, e a busca pelo rejuvenescimento é nos dias atuais uma preocupação comum em muitas mulheres de diferentes gerações do Brasil. Em geral, as mulheres são consumidoras das técnicas e produtos amplamente divulgados pelos setores midiáticos. A comunicação social, nas relações entre indivíduos, aparece como condição de possibilidade e de determinação das representações e dos pensamentos sociais, como coloca Jodelet ${ }^{10}$ (2001).

Há três possibilidades de comunicação praticadas pelos órgãos da imprensa: a difusão, a propagação e a propaganda. "[...] $A$ difusão é caracterizada por uma indiferenciação entre a fonte e os receptores da comunicação [...]. Seu objetivo principal é, ao mesmo tempo, criar um saber comum e adaptar-se aos interesses de seu público. A relação de propagação é estabelecida pelos membros de um grupo que produг uma visão do mundo bem organizada, que dispõe de uma crença a propagar, esforcando-se para acomodar outros saberes a este quadro estabelecido [...]. A propaganda é uma forma de comunicaşão que se inscreve em relaçöes sociais conflituosas [...]" (Jodelet ${ }^{10}$ 2001, p. 191).

A mídia postula que o bem-estar emocional depende dos aspectos físicos, da beleza do corpo, e que a velhice e o passar do tempo, que anteriormente eram correspondentes a sabedoria e experiência, devem ser adiados a qualquer custo. É no corpo que se colocam muitas das expectativas do futuro.

\section{A teoria da representação social}

Ao propor a teoria das representações sociais, Serge Moscovici diferenciou-se da teoria das representações coletivas de Durkheim ${ }^{6}$ (1963), que são pensamentos acumulados e associados durante muito tempo, passados de 
geração para geração, abrangem uma gama muito ampla e heterogênea de conhecimentos e não são facilmente modificados (Moscovici $^{13}$, 1978). São entidades irredutíveis e absolutas, assim como os mitos e os ditados populares. Já as representações sociais, segundo Moscovici ${ }^{13}$ (1978), são elaborações e explicações da linguagem e dos comportamentos contemporâneos de senso comum, localizando-se num ponto de intersecção do psicológico e do social. Desempenham papel importante na construção e preservação das identidades grupais e na integração dos indivíduos e grupos sociais. "Por representação social nós queremos dizer um conjunto de conceitos, afirmações e explicações originadas no curso do cotidiano, no curso das comunicações interindividuais. Elas são equivalentes, em nossa sociedade, aos mitos e sistemas de crenças das sociedades tradicionais; elas podem até mesmo ser vistas como uma versão contemporânea de senso comum" (Moscovici'14, 1981, p. 181).

Durante as conversas do dia-a-dia e nas interações sociais formam-se as representações sociais. São fenômenos psicossociais histórica e culturalmente condicionados. Quando se trabalha com o conceito de representação, se está pressupondo que é uma forma de saber muito prático que liga um grupo de sujeitos a um ou vários objetos. Um objeto cuja natureza, afirma Sá20 (1996), pode ser social, material ou ideal. O tema que é objeto deste estudo pode ser categorizado muitas vezes como um objeto vezes material e real (encontrar-se vivenciando a velhice), ou ideal (pensar na velhice, pensar em rejuvenescimento, almejar rejuvenescer, etc.), mas que espreme um profundo condicionamento social. A representação simboliza o objeto, confere-lhe um significado, é uma construção desse sujeito em seu grupo; ele a utiliza para se expressar e, ao mesmo tempo, regula e controla o comportamento desse sujeito.

Segundo Moscovici ${ }^{13}$ (1978), os processos formadores de uma representação social são, basicamente, a ancoragem e a objetivação. Ancorar um assunto significa integrar cognitivamente um determinado objeto no pensamento social que já existe no sujeito. Durante a ancoragem ocorrem diversas transformações nesse processo, que implicam classificar e rotular tudo aquilo que parece estranho e que fica sem classificação e nomeação. Muitas vezes isso determina uma certa objetivação, que consiste na transformação do significado do pensamento abstrato em algo imagético, concreto, que representará o objeto e o diferenciará de outros (Sá20 ${ }^{20}$ 1996). A objetivação explica uma operação imaginante e estruturante, no sentido de dar forma ao conhecimento acerca de determinado assunto, tornando-o concreto, tangível e material a partir de certas palavras mais icônicas. É o processo que permite compreender a formação de uma estrutura denominada "núcleo figurativo" - aquelas palavras que conseguem expressar de maneira imagética um conjunto de idéias. A ancoragem e a objetivação são processos que estão envolvidos na noção de como o social se transforma em representação e como esta, por sua vez, transforma o social (Sá20 ${ }^{20}$ 1996; Moscovici $\left.{ }^{13}, 1978\right)$.

Conforme afirma Jodelet ${ }^{10}$ (2001), o ato de representar possui algumas características fundamentais: é sempre a representação de um objeto; tem caráter de imagem e contém 
a possibilidade de poder-se trocar a idéia pelo sensível, a percepção pelo concreto; possui caráter simbólico e significante; tem caráter construtivo; autônomo e criativo. Esse ato de representar leva algo social, quer dizer, aquelas categorias que o estruturam e o expressam são tomadas de um fundo comum de cultura, são categorias da linguagem.

\section{Teoria do núcleo central}

A teoria do núcleo central foi proposta em 1976 por Abric ${ }^{1}$ (1998) e estabelece que a representação social possui uma organização interna que diferencia conteúdos centrais dos periféricos.

O núcleo central é a parte mais estável da representação, seu caráter imutável faz com que pouco se influencie com o contexto imediato. É rígido e coerente, ligado à memória coletiva e à história do grupo. "Constitui a base comum, compartilhada e consensual da representação social' (Sá20, 1996, p. 70-71). Garante a homogeneidade do grupo, já que uma de suas funções é fornecer continuidade e permanência à representação. O núcleo central se estabelece quando se dá a interação significativa; ele estrutura como a situação é representada e, em conseqüência, determina o comportamento dos sujeitos. Sua ligação com a representação é tão intrínseca que, à medida que acontece uma mudança no núcleo central da representação social, espera-se uma variação da representação como um todo e diz-se que quando há duas representações sociais haverá, provavelmente, mais de um núcleo central. O núcleo central é "um subconjunto da representação, composto de um ou alguns elementos cuja ausência desestruturaria a própria representação ou the daria uma significação completamente diferente" (Abric apudSá, ${ }^{20}, 1996$, p. 67).

Uma das funções mais importantes do núcleo central é a organizadora. Sendo assim, seus conteúdos agem como elementos unificadores, estabilizadores e geradores que tomam sentido e conferem significado à própria representação. Possui também uma dimensão funcional, no sentido de explicar o funcionamento de práticas, hábitos e atitudes que estão presentes no cotidiano. A dimensão normativa relaciona-se com aqueles conteúdos de caráter mais informativo e conceitual. Um aspecto importante da relação entre as dimensões é que, em geral, quando o grupo utiliza a representação com fins operatórios ou funcionais, isto é, para regular as práticas, significa que esse grupo conhece e já possui certas normas sobre o objeto da representação em questão.

Os aspectos ou sistemas periféricos da representação são indispensáveis, pois permitem a integração das experiências e histórias individuais, assim como uma adaptação à realidade, justificando seu caráter maleável, flexível e evolutivo. Protege o núcleo ou sistema central, já que suporta a heterogeneidade e contradições, envolvendo prescrições condicionais. O funcionamento do núcleo central não se compreende, senão, em dialética contínua com a periferia (Flament $\left.{ }^{7}, 2001\right)$.

Para um melhor entendimento, pode-se exemplificar com uma figura, acreditada como atual: um adolescente que compartilha com seus amigos a idéia de que o idoso é 
inútil (núcleo central); na medida em que o tempo passa, lê sobre o atleta idoso, observa seu avô freqüentando bailes de terceira idade, fica sabendo de um empresário que tem 70 anos de idade... (conteúdos do possível núcleo periférico), podendo assim acrescentar essas informações ao seu conceito original ou até mudar sua representação (núcleo central).

\section{METODOLOGIA}

\section{Participantes}

Participaram da pesquisa três grupos de mulheres, sendo o primeiro caracterizado por 34 mulheres de 25 a 35 anos, o segundo por 18 mulheres entre 40 e 50 anos e o terceiro por 20 mulheres acima de 60 anos de idade. Para a caracterização geral da amostra, foi usado um questionário que explorava alguns dados de identificação geral dos sujeitos.

Os dados permitiram caracterizar a amostra da seguinte maneira: no total participaram do estudo 72 mulheres, distribuídas por diferentes faixas etárias em três grupos. No grupo de 25 a 35 anos, 65\% delas têm nível superior incompleto; 94\% disseram ser a favor de tratamentos para o rejuvenescimento, apesar de só 7\% das mesmas terem se submetido aos mesmos. Isso pode ser justificado pelo fato de essas mulheres serem jovens e, talvez por isso, ainda não necessitarem dos tratamentos. No grupo de mulheres de 40 a 50 anos, $88 \%$ se mostraram favoráveis ao uso de tratamentos de rejuvenescimento e, de fato, 22,2\% delas já os tinham utilizado. Este foi o grupo que apresentou renda média maior -
$62,5 \%$ possuem em torno de $\mathrm{R} \$ 3.900$, o que talvez favoreça o acesso a esses tratamentos para rejuvenescimento. O grupo de mulheres acima de 60 anos se caracterizou, em sua maioria $(80 \%)$, por possuir renda média de $\mathrm{R} \$$ $2.065 ; 82,3 \%$ posicionaram-se a favor dos tratamentos, mas apenas 15\% tinham utilizado algum tipo de tratamento para rejuvenescer.

\section{Material e instrumento de coleta de dados}

Foi utilizada a técnica de associação livre de palavras para a coleta dos dados, que é um dos métodos de levantamento dos possíveis elementos do núcleo central. Envolve a colocação em evidência das propriedades de saliência e de conexidade dos diferentes elementos de uma representação, permitindo um levantamento hipotético inicial daqueles mais suscetíveis de fazer parte do núcleo central e a formulação de hipóteses quanto à constituição do mesmo (Sá20, 1996).

Abric $^{1}$ (1998) coloca que a técnica de associação livre, em relação à entrevista, tem um caráter mais espontâneo e menos controlado, permitindo a projeção e o acesso muito mais fácil aos elementos que constituem o universo das representações do objeto estudado. A associação livre permite a atualização de elementos implícitos ou latentes que seriam perdidos ou mascarados nas produções discursivas. A análise de dados foi realizada por meio da freqüência absoluta de cada palavra evocada e pela ordem média de evocação de cada palavra (a ordem média de cada palavra é calculada, assim, como a média das ordens médias em que elas foram evocadas pelos diversos sujeitos, atribuindo-se peso " 1 " 
a uma evocação em primeiro lugar, peso " 2 ” a uma evocação em segundo lugar e assim por diante). A combinação da análise da freqüência de evocação e da ordem média de cada palavra possibilitou o levantamento de conteúdos que provavelmente pertenciam ao núcleo central e que, segundo Abric ${ }^{1}$ (1998), permitiriam criar um conjunto de categorias organizadas em torno desses termos, para assim confirmar as indicações sobre seu papel organizador das representações.

A intersecção desses dados permitiu a elaboração de quatro quadrantes que conferem diferentes graus de centralidade às palavras que os compõem. Nos dois quadrantes superiores estão localizadas palavras ditas com freqüência maior e nos inferiores estão situadas as palavras ditas com menor freqüência. Já nos quadrantes da esquerda encontram-se as palavras mais prontamente evocadas e nos da direita as menos prontamente evocadas. Conclui-se que o quadrante superior esquerdo representa os possíveis elementos do núcleo central e que os quadrantes restantes representam os possíveis elementos do núcleo periférico. No trabalho foram usados dois termos indutores, na seqüência: "envelhecimento" e "rejuvenescimento". Foram solicitadas, para cada termo, três palavras em livre associação. Pretendeu-se com essas evocações conhecer quais as representações que os sujeitos da pesquisa têm sobre ambos os assuntos.

\section{Procedimento e análise de dados}

O estudo, de tipo exploratório, utilizou na análise de dados uma abordagem qualitativa.
A coleta de dados foi feita por meio da técnica de associação livre de palavras. A análise das evocações foi feita seguindo a proposta de Vergès, do cálculo de freqüência e da ordem média de evocação (Vergès $\left.{ }^{31}, 1992\right)$. Por meio dessa técnica de organização de dados de pesquisa, foram identificadas a organização e a saliência de conteúdo da representação social de assuntos ligados aos objetos de estudo: envelhecimento e rejuvenescimento.

\section{DISCUSSÃO DE RESULTADOS}

Os resultados de pesquisa discutidos aqui correspondem a uma primeira etapa na análise da estrutura da representação social dos assuntos norteadores do estudo. Outras etapas da pesquisa incluíram a aplicação de uma técnica de grupo focal, com alvo na discussão sobre os temas de envelhecimento e rejuvenescimento, assim como da aplicação de uma técnica de triagem hierarquizada sucessiva, para confirmar a saliência dos conteúdos centrais e periféricos das representações sociais obtidos nas evocações que foram objeto de outros trabalhos já publicados (Teixeira et al. ${ }^{24}, 2006$; Teixeira et al. ${ }^{25}$, no prelo). No presente artigo serão discutidos apenas os resultados da primeira etapa da análise sobre o levantamento do conteúdo da representação a partir do método interrogativo, com a correspondente análise da saliência desses conteúdos.

O conjunto de evocações, segundo o termo indutor "envelhecimento" nos três grupos, pode ser observado nos quadros 1,2 e 3 . 
Quadro 1 - Estrutura da representação social sobre o assunto "envelhecimento" em um grupo de estudantes universitárias pela freqüência e pela média de evocação.

\begin{tabular}{|c|c|c|c|c|c|}
\hline Palavras & $\begin{array}{l}\text { F.M.E. * } \\
>2,3\end{array}$ & $\begin{array}{l}\text { O.M.E. }{ }^{* *} \\
<2,1\end{array}$ & Palavras & $\begin{array}{l}\text { F.M.E. * } \\
>2,3\end{array}$ & $\begin{array}{l}\text { O.M.E. }{ }^{* *} \\
\geq 2,1\end{array}$ \\
\hline Rugas & 12 & 1,8 & $\begin{array}{l}\text { Debilidade/ Fragilidade/ } \\
\text { Enfraquecimento }\end{array}$ & 3 & 3 \\
\hline Experiência & 11 & 1,7 & História & 3 & 2,3 \\
\hline Sabedoria & 11 & 1,9 & Flacidez & 3 & 2,3 \\
\hline \multicolumn{6}{|l|}{ Maturidade/ Maturação/ } \\
\hline Amadurecimento & 8 & 1,5 & & & \\
\hline Medo & 3 & 1,6 & & & \\
\hline Idade/ Idade avançada & 3 & 1 & & & \\
\hline Solidão/ Isolamento & 4 & 2 & & & \\
\hline \multirow[t]{2}{*}{ Palavras } & F.M.E. * & O.M.E. ${ }^{* *}$ & Palavras & F.M.E. * & O.M.E. ** \\
\hline & $\leq 2,3$ & $<2,1$ & & $\leq 2,3$ & $\geq 2,1$ \\
\hline Natural & 2 & 1 & Fim & 2 & 2,5 \\
\hline Preconceito & 2 & 2 & Inevitável/ Certo & 2 & 3 \\
\hline Cabelos brancos & 2 & 1,5 & Frustração & 1 & 3 \\
\hline Descanso/ Tranqüilidade & 2 & 2 & Perda de credibilidade & 1 & 3 \\
\hline Limitador & 1 & 2 & Dor & 1 & 3 \\
\hline Qualidade de vida & 1 & 2 & Aposentadoria & 1 & 3 \\
\hline Crítica & 1 & 2 & Vida & 1 & 3 \\
\hline Dific. De memorização & 1 & 2 & Vida mais curta & 1 & 3 \\
\hline Dificuldade & 1 & 1 & Impossibilidade & 1 & 3 \\
\hline Família & 1 & 2 & Neto & 1 & 3 \\
\hline Rejeição & 1 & 1 & Vivência & 1 & 3 \\
\hline Cinza & 1 & 2 & Mente & 1 & 3 \\
\hline Corpo & 1 & 2 & Realização & 1 & 3 \\
\hline Face & 1 & 2 & Encanto & 1 & 3 \\
\hline Perda da auto-estima & 1 & 2 & Decadência & 1 & 3 \\
\hline Satisfação & 1 & 2 & & & \\
\hline Parar no tempo & 1 & 1 & & & \\
\hline Doença & 1 & 1 & & & \\
\hline Inadaptabilidade & 1 & 2 & & & \\
\hline Perda de beleza & 1 & 2 & & & \\
\hline
\end{tabular}

* F.M.E.: Freqüência Média de Evocação das Palavras

** O.M.E.: Ordem Média de Evocação das Palavras 
As hipóteses de conteúdos de núcleos centrais nos três grupos pesquisados permitiram identificar a presença de palavras e expressões que apontaram para uma dimensão normativa do assunto envelhecimento: vários termos descreveram o envelhecimento no sentido de "experiência", "sabedoria" e "rugas", sendo estas heranças da antigüidade que ainda continuam estagnadas e estereotipadas na sociedade como forma de representação do envelhecimento $\left(\mathrm{Sá}^{20}, 1996\right)$.

Quadro 2 - Estrutura da representação social sobre o assunto "envelhecimento" em um grupo de mulheres de 40 a 50 anos pela freqüência e pela média de evocação.

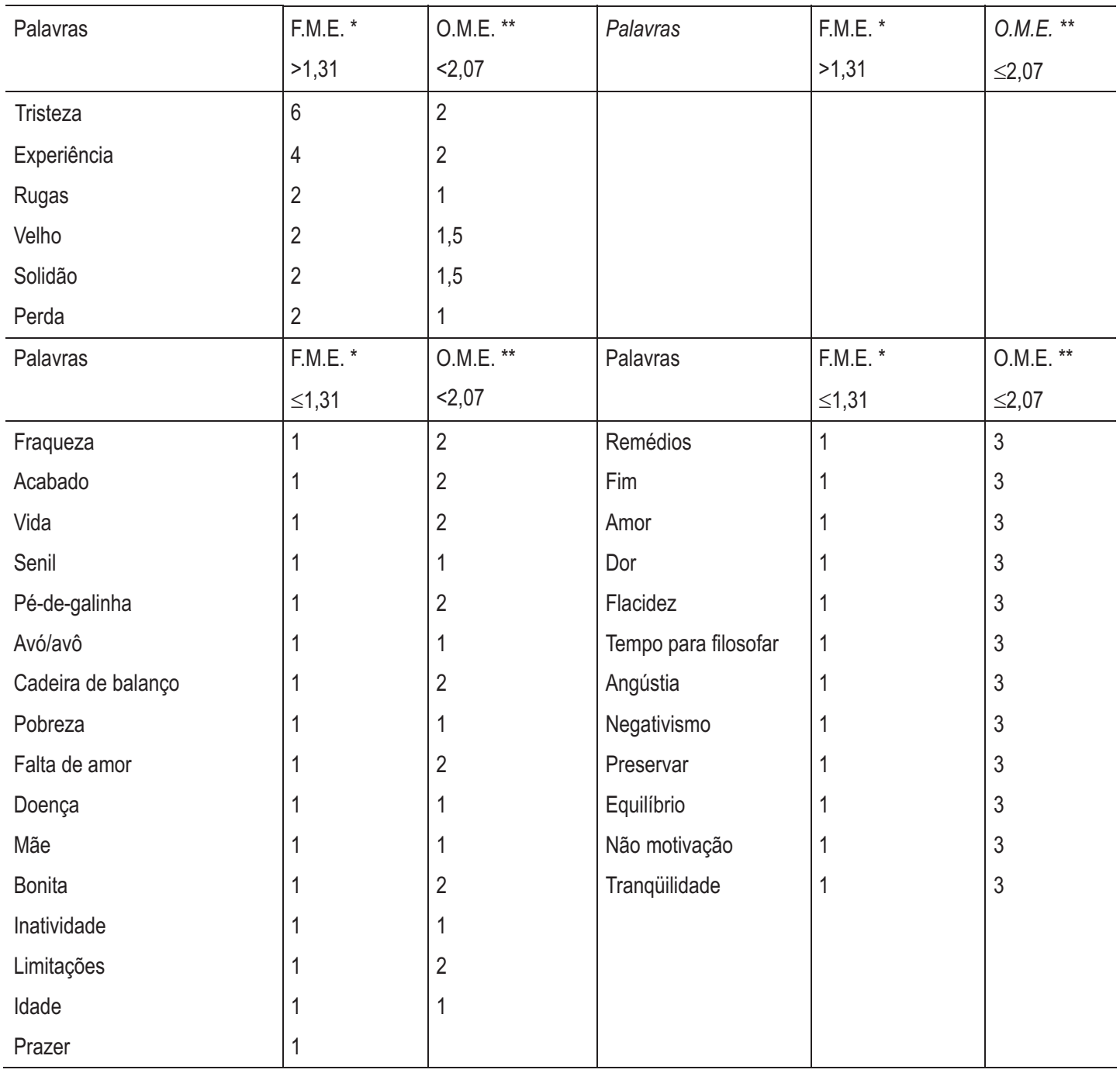

* F.M.E.: Freqüência Média de Evocação das Palavras

** O.M.E.: Ordem Média de Evocação das Palavras 
A análise permitiu também perceber que há uma dicotomia no conteúdo dos termos, ou seja, existem termos que descrevem conteúdos positivos do envelhecimento e outros que descrevem aspectos negativos. No grupo de mulheres universitárias de 25 a 35 anos, houve uma equivalência nos dois aspectos e a ocorrência de um termo merecedor de maior atenção: medo (quadro 1). Compreendese o aparecimento desse termo pelo fato de essas jovens se encontrarem numa faixa etária distante do envelhecimento, sendo natural a emissão desse sentimento de medo perante contingências que elas ainda não vivenciaram.
No grupo de mulheres de 40 a 50 anos, houve predominância dos termos negativos, merecendo destaque a palavra "perda" (quadro 2). Talvez o termo reflita o sentimento que esse grupo está começando a vivenciar com a entrada em uma nova realidade, visto que é dentro dessa faixa etária que as pessoas começam a perder alguns sinais físicos da juventude, assim como certos comportamentos de vigor que caracterizavam fases anteriores do desenvolvimento. 
Quadro 3 - Estrutura da representação social sobre o assunto "envelhecimento" em um grupo de mulheres com mais de 60 anos pela freqüência e pela média de evocação.

\begin{tabular}{|c|c|c|c|c|c|}
\hline Palavras & $\begin{array}{l}\text { F.M.E. * } \\
>1,3\end{array}$ & $\begin{array}{l}\text { O.M.E. ** } \\
<2,1\end{array}$ & Palavras & $\begin{array}{l}\text { F.M.E. * } \\
>1,3\end{array}$ & $\begin{array}{l}\text { O.M.E. }{ }^{* *} \\
\geq 2,1\end{array}$ \\
\hline Experiência & 4 & 1,75 & Rugas & 2 & 3 \\
\hline Sabedoria & 3 & 1,3 & & & \\
\hline Maturidade/ Amadurecimento & 3 & 2 & & & \\
\hline Perda de memória & 2 & 1,5 & & & \\
\hline Vivência & 2 & 2 & & & \\
\hline Paz/Tranqüilidade & 2 & 1,5 & & & \\
\hline Viver com amor/ Amor & 2 & 2 & & & \\
\hline Dor & 2 & 2 & & & \\
\hline \multirow[t]{2}{*}{ Palavras } & F.M.E. * & O.M.E. ** & Palavras & F.M.E. * & O.M.E. ** \\
\hline & $\leq 1,3$ & $<2,1$ & & $\leq 1,3$ & $\geq 2,1$ \\
\hline Certeza & 1 & 2 & Abatimento & 2 & 2,5 \\
\hline Limitação Física & 1 & 1 & Eternidade & 2 & 3 \\
\hline Natural & 1 & 1,5 & Sofrimento & 1 & 3 \\
\hline Normal & 1 & 2 & Bonito & 1 & 3 \\
\hline Alegria & 1 & 2 & Etapas da vida & 1 & 3 \\
\hline Gostoso & 1 & 1 & Bom ser avó & 1 & 3 \\
\hline Boa fase da vida & 1 & 1 & Aprende a entender mais as pessoas & 1 & 3 \\
\hline Depressão & 1 & 1 & Solidão & 1 & 3 \\
\hline Tristeza & 1 & 1 & Aproveitar & 1 & 3 \\
\hline Ânimo & 1 & 2 & Ter sempre o que fazer & 1 & 3 \\
\hline Prazer & 1 & 2 & Acerto & 1 & 3 \\
\hline Rejuvenescer & 1 & 1 & Indisposição & 1 & 3 \\
\hline Alimentar & 1 & 2 & Não ter esperanças e sonhos & 1 & 3 \\
\hline Idade & 1 & 1 & Liberdade & 1 & 3 \\
\hline Conseqüência & 1 & 1 & & & \\
\hline Estagnação Cerebral & 1 & 1 & & & \\
\hline Perda da auto-estima & 1 & 2 & & & \\
\hline Falta de agilidade & 1 & 2 & & & \\
\hline Saudades do passado & 1 & 2 & & & \\
\hline
\end{tabular}

* F.M.E.: Freqüência Média de Evocação das Palavras

** O.M.E.: Ordem Média de Evocação das Palavras 
Já no grupo de mulheres acima de 60 anos predominou uma avaliação positiva do envelhecimento (sabedoria, maturidade, experiência, paz e amor-quadro 3). Apenas dois termos descreveram aspectos negativos. Entre eles, enfatizou-se a palavra "dor" que se acredita ser uma expressão simbólica relativa a perdas psicológicas ou até doenças, cuja prevalência aumenta na medida em que a pessoa se aproxima da velhice. A palavra "dor" também apareceu nos grupos de mulheres entre 25 e 35 anos e entre 40 e 50 anos, só que fazendo parte dos conteúdos do núcleo periférico (quadros 1 e 2), o que caracteriza uma representação que não é compartilhada pela maioria, podendo sofrer alterações por estar distante de suas realidades.

As hipóteses de núcleos periféricos próximos e distantes das mulheres entre 25 e 35 anos e entre 40 e 50 anos (quadros 1 e 2) apontaram para uma predominância dos aspectos negativos sobre os positivos, por exemplo: decadência, depressão, pobreza, doença, perda de auto-estima, dor, fraqueza, acabado, angústia, limitação e rejeição, dentre outros (quadros 1 e 2). Já no grupo acima de 60 anos (quadro 3), houve predomínio de aspectos positivos (alegria, bonito, prazer, gostoso, certeza, ânimo, bom ser avó, liberdade (quadro 3). Isso mostra que o envelhecimento, para essas participantes, não adota um significado tão estereotipado e negativo. Quando essas mulheres representam o envelhecimento, os aspectos negativos apontam para condições objetivas que acompanham a fase da velhice, no caso: falta de agilidade, solidão, indisposição, tristeza e limitações físicas (quadro 3).
Chama a atenção que, no caso das mulheres entre 25 e 35 e entre 40 e 50 anos, o sentido negativo de algumas das palavras encontradas foi diferente e até mais irreal, descrevendo uma velhice futura muito mais limitada que a velhice vivida pelo grupo acima de 60 anos (palavras: parar no tempo, inadaptabilidade, perda de credibilidade, frustração, decadência, acabado, fim, angústia, baixo astral - quadros 1 e 2). Acredita-se que os conteúdos dos núcleos periféricos das mulheres que chegaram a essa etapa da vida apresentam um caráter maleável, flexível, evolutivo e mais sensível ao contexto imediato $\left(\mathrm{Sá}^{20}, 1996\right)$. Isso representa aquilo que a pessoa está vivenciando durante a etapa, e por isso há uma distinção entre os núcleos periféricos da representação social deste grupo em relação aos outros dois.

Assim como no núcleo central, o núcleo periférico também apresentou predominância da dimensão normativa, pois descreve o inevitável, que são o processo do envelhecimento e a entrada na fase da velhice. O termo "envelhecimento" possibilitou o surgimento de núcleos figurativos, como cinza e cadeira de balanço, que se caracterizam por serem uma estrutura imagética que reproduz um conceito de maneira visível (Moscovici ${ }^{13}$, 1978). Por exemplo, o cinza nos remete à idéia de cabelos cinza, de cinzas resultantes da morte, de ser uma cor triste e sem graça; da mesma forma, a cadeira de balanço nos remete à idéia de ócio, estagnação, incapacidades físicas e doenças em geral. 
Quadro 4 - Estrutura da representação social sobre o assunto "rejuvenescimento" em um grupo de estudantes universitárias pela freqüência e pela média de evocação.

\begin{tabular}{|c|c|c|c|c|c|}
\hline Palavras & $\begin{array}{l}\text { F.M.E. * } \\
>1,69\end{array}$ & $\begin{array}{l}\text { O.M.E. }{ }^{* *} \\
<2,06\end{array}$ & Palavras & $\begin{array}{l}\text { F.M.E. }{ }^{*} \\
>1,69\end{array}$ & $\begin{array}{l}\text { O.M.E. }{ }^{*} \\
\geq 2,06\end{array}$ \\
\hline Alegre /Alegria/ Felicidade & 8 & 2 & Cuidado & 4 & 2,25 \\
\hline Beleza & 8 & 1,87 & Vaidade & 2 & 3 \\
\hline Energia/ Estar ativo/ Disposta/ Vigor/ Vida/ Vivacidade & 6 & 1,6 & Bem-estar & 2 & 3 \\
\hline Saudável/ Saúde & 5 & 1,6 & & & \\
\hline Jovialidade/ Jovem/ Juventude & 4 & 1,25 & & & \\
\hline Auto-estima & 4 & 1.25 & & & \\
\hline Aparência/ Externo & 2 & 1,5 & & & \\
\hline Bom & 2 & 1,5 & & & \\
\hline Renovação & 2 & 1,5 & & & \\
\hline Estética & 2 & 1,5 & & & \\
\hline Bobagem & 2 & 2 & & & \\
\hline Cirurgia-plástica & 2 & 1 & & & \\
\hline Necessário & 2 & 2 & & & \\
\hline Palavras & F.M.E.* & O.M.E. ${ }^{* *}$ & Palavras & F.M.E. ${ }^{*}$ & O.M.E. ** \\
\hline & $\leq 1,69$ & $<2,06$ & & $\leq 1,69$ & $\geq 2,06$ \\
\hline Consciência & 1 & 1 & Pele lisinha & 1 & 3 \\
\hline Conhecimento & 1 & 2 & Possivel & 1 & 3 \\
\hline Brincadeiras & 1 & 2 & Novidades & 1 & 3 \\
\hline Fuga & 1 & 1 & Gasto & 1 & 3 \\
\hline Impossível & 1 & 2 & Rugas & 1 & 3 \\
\hline Recordar & 1 & 1 & Aceitação & 1 & 3 \\
\hline Busca & 1 & 1 & Calma & 1 & 3 \\
\hline Prazer & 1 & 2 & Alimentação & 1 & 3 \\
\hline Dúvida & 1 & 1 & Tratamentos & 1 & 3 \\
\hline Ilusão & 1 & 1 & Cosmético & 1 & 3 \\
\hline Elegância & 1 & 2 & Mudança & 1 & 3 \\
\hline Desejável & 1 & 2 & Hobby & 1 & 3 \\
\hline Lipoaspiração & 1 & 2 & Se amar & 1 & 3 \\
\hline Pílulas & 1 & 2 & Mente sã & 1 & 3 \\
\hline Amizade & 1 & 2 & Insegurança & 1 & 3 \\
\hline Realização & 1 & 2 & Eternidade & 1 & 3 \\
\hline Segurança & 1 & 2 & & & \\
\hline Filhos & 1 & 1 & & & \\
\hline Amor de marido & 1 & 2 & & & \\
\hline Chance & 1 & 1 & & & \\
\hline Vontade de viver & 1 & 1 & & & \\
\hline
\end{tabular}

* F.M.E.: Freqüência Média de Evocação das Palavras, ** O.M.E.: Ordem Média de Evocação das Palavras 
O outro termo a ser discutido é "rejuvenescimento”. As hipóteses de núcleo central de todas as participantes mostraram uma saliência a partir de vocábulos relacionados com aspectos positivos que remetem tanto a fatores físicos (como por exemplo, estética, aparência e cirurgia plástica); quanto à qualidade de vida (como caminhada, energia e saúde), mostrando que, para essas mulheres, rejuvenescer não é apenas apagar traços físicos do envelhecimento, mas manter o bem-estar geral e fazer atividades que permitam prevenir alguns tipos de doenças. Notou-se também no núcleo central a presença de termos que representam a dimensão normativa, a qual descreve e normatiza o rejuvenescimento como alegria, e termos que representam uma dimensão funcional, como cirurgia plástica e exercícios físicos, no sentido de práticas em prol de rejuvenescer. 
Quadro 5 - Estrutura da representação social sobre o assunto "rejuvenescimento" em um grupo de mulheres de 40 a 50 anos pela freqüência e pela média de evocação.

\begin{tabular}{|c|c|c|c|c|c|}
\hline Palavras & $\begin{array}{l}\text { F.M.E. * } \\
>1,54\end{array}$ & $\begin{array}{l}\text { O.M.E. }{ }^{* *} \\
<2,01\end{array}$ & Palavras & $\begin{array}{l}\text { F.M.E. * } \\
>1,54\end{array}$ & $\begin{array}{l}\text { O.M.E. * } \\
\leq 2,01\end{array}$ \\
\hline Beleza & 6 & 1,83 & Satisfação & 2 & 3 \\
\hline Alegria & 5 & 1,6 & Auto-estima & 2 & 2,5 \\
\hline Bem-estar & 4 & 1,75 & & & \\
\hline Saúde & 3 & 2 & & & \\
\hline Dúvida & 2 & 2 & & & \\
\hline Renovação & 2 & 1 & & & \\
\hline Energia & 2 & 2 & & & \\
\hline Palavras & $\begin{array}{l}\text { F.M.E. * } \\
\leq 1,54\end{array}$ & $\begin{array}{l}\text { O.M.E. }{ }^{* *} \\
<2,01\end{array}$ & Palavras & $\begin{array}{l}\text { F.M.E. * } \\
\leq 1,54\end{array}$ & $\begin{array}{l}\text { O.M.E. }{ }^{*} \\
\leq 2,01\end{array}$ \\
\hline Vigor & 1 & 1 & Sorriso & 1 & 3 \\
\hline Novidade & 1 & 1 & Nascimento & 1 & 3 \\
\hline Despesas & 1 & 2 & Pele viçosa & 1 & 3 \\
\hline Sem rugas & 1 & 2 & Beleza estereotípica & 1 & 3 \\
\hline Juventude & 1 & 2 & Viva & 1 & 3 \\
\hline Vida & 1 & 1 & Motivação & 1 & 3 \\
\hline Frescor & 1 & 2 & Felicidade & 1 & 3 \\
\hline Negação & 1 & 1 & Valorização & 1 & 3 \\
\hline Valor externo & 1 & 2 & Interessante & 1 & 3 \\
\hline Bom & 1 & 2 & & & \\
\hline Sucesso & 1 & 2 & & & \\
\hline Cuidado & 1 & 1 & & & \\
\hline Mente & 1 & 1 & & & \\
\hline Otimismo & 1 & 1 & & & \\
\hline Vitalidade & 1 & 2 & & & \\
\hline Auto-astral & 1 & 1 & & & \\
\hline Prazer & 1 & 2 & & & \\
\hline
\end{tabular}

* F.M.E.: Freqüência Média de Evocação das Palavras

** O.M.E.: Ordem Média de Evocação das Palavras 
Na hipótese de núcleo central dos três grupos apareceu o vocábulo "alegria". Ao discutir as relações causais entre rejuvenescimento e alegria, cabem duas hipóteses: a primeira pode estar associada com a alegria como possível causa ou fator para se manter jovem; e a segunda, relacionada com a alegria como conseqüência do processo de rejuvenescer.

Houve uma dicotomia nos conteúdos de núcleo central do grupo de mulheres de $25 \mathrm{a}$ 35 anos que merece atenção: "necessário" e "bobagem" (quadro 4). A mídia propaga atualmente os métodos de rejuvenescimento e difunde a idéia de que é possível voltar a ser jovem. No Brasil, exemplo disso foi uma capa da revista Playboy, na qual mãe e filha posaram juntas, parecendo ser da mesma geração $(R e-$ vista Playboy ${ }^{19}$, 2003). Talvez por essa influência da mídia, o comportamento de procura de métodos de rejuvenescimento por muitas mulheres esteja sendo influenciado pelo estímulo de acreditar na possibilidade de deter os efeitos do tempo sobre o corpo, ou rejuvenescer um corpo envelhecido a ponto de lhe dar uma aparência de dez anos menos. Nesse sentido, as mídias impressa e televisiva exercem um forte papel de propaganda e propagação (Doise ${ }^{5}, 2001$; Jodelet ${ }^{10}$, 2001). Por outro lado, sabe-se que chegar aos 60 anos com o corpo e a pele de 20 é impossível, e é provável que as mulheres, tendo consciência disso, evocaram o vocábulo "bobagem" associado ao rejuvenescimento (quadro 4). 
Quadro 6 - Estrutura da representação social sobre o assunto "rejuvenescimento" em um grupo de mulheres com mais de 60 anos pela freqüência e pela média de evocação.

\begin{tabular}{|c|c|c|c|c|c|}
\hline Palavras & $\begin{array}{l}\text { F.M.E. * } \\
>1,3\end{array}$ & $\begin{array}{l}\text { O.M.E. ** } \\
<1,9\end{array}$ & Palavras & $\begin{array}{l}\text { F.M.E. * } \\
>1,3\end{array}$ & $\begin{array}{l}\text { O.M.E. ** } \\
\geq 1,9\end{array}$ \\
\hline Alegria/ Felicidade & 5 & 1,8 & Espiritual/Estado de espírito & 2 & 2 \\
\hline Caminhada/ Exercícios Físicos & 2 & 1,5 & Jovem/ Mocidade & 2 & 2 \\
\hline \multirow[t]{3}{*}{ Insegurança/ incerteza } & \multirow[t]{3}{*}{2} & \multirow[t]{3}{*}{1,5} & Saúde & 2 & 2,5 \\
\hline & & & Lazer & 2 & 2 \\
\hline & & & Beleza & 2 & 2 \\
\hline \multirow[t]{2}{*}{ Palavras } & F.M.E. * & O.M.E. ${ }^{* *}$ & \multirow[t]{2}{*}{ Palavras } & F.M.E. * & O.M.E. ** \\
\hline & $\leq 1,3$ & $<1,9$ & & $\leq 1,3$ & $\geq 1,9$ \\
\hline Sonho de alguns & 1 & 1 & Perigoso & 1 & 2 \\
\hline Vida & 1 & 1 & Pele Jovial & 1 & 3 \\
\hline Não é bom & 1 & 1 & Caro & 1 & 3 \\
\hline Hidroginástica & 1 & 1 & Cabelos Brilhantes & 1 & 2 \\
\hline Bem estar & 1 & 1 & Artificial & 1 & 2 \\
\hline Cor & 1 & 1 & Trabalhoso & 1 & 3 \\
\hline Força & 1 & 1,5 & Futilidade & 1 & 2 \\
\hline Equilíbrio Emocional & 1 & 1 & Vaidade & 1 & 3 \\
\hline Muito bom & 1 & 1 & Mentira & 1 & 2 \\
\hline \multirow[t]{9}{*}{ Fazer o que gosta } & \multirow[t]{9}{*}{1} & \multirow[t]{9}{*}{1} & Decepção & 1 & 3 \\
\hline & & & Auto estima & 1 & 2 \\
\hline & & & Indefinição & 1 & 3 \\
\hline & & & Bobagem & 1 & 2 \\
\hline & & & Alimentação & 1 & 3 \\
\hline & & & Plástica & 1 & 3 \\
\hline & & & Filosofia e vida & 1 & 2 \\
\hline & & & Equilíbrio Mental & 1 & 2 \\
\hline & & & Brilho nos Olhos & 1 & 3 \\
\hline
\end{tabular}

* F.M.E.: Freqüência Média de Evocação das Palavras

** O.M.E.: Ordem Média de Evocação das Palavras 
Ainda analisando as hipóteses do núcleo central, o grupo entre 40 e 50 anos evocou o termo "dúvida" e o grupo acima de 60 evocou os vocábulos "insegurança” e "incerteza" (quadros 5 e 6 , respectivamente). São palavras diferentes, mas que remetem ao mesmo significado. Compreende-se que, para essas mulheres, voltar a ser jovem implica insegurança e incerteza, pela razão de, provavelmente, não acreditarem que de fato existem possibilidades reais e irreversíveis de fazer com que o tempo volte atrás.

Deve-se enfatizar que, embora tenham sido evocadas palavras referentes à prevenção, houve também, nas hipóteses de núcleos centrais dos grupos entre 25 e 35 anos e entre 40 e 50 anos, a presença da palavra beleza (quadros 4 e 5). Já no núcleo central do grupo acima de 60 anos, o termo "beleza" não apareceu, mas notou-se sua presença no núcleo periférico próximo, refletindo que para essas mulheres idosas, talvez por já estarem vivenciando a velhice, rejuvenescer está além de uma questão de aparência.

A análise dos vocábulos que fazem parte das hipóteses do núcleo central do grupo entre 25 e 35 anos confirmou que rejuvenescer, para essas jovens universitárias, como já foi dito, não é apenas cuidar da beleza externa, mas também prevenir problemas de saúde, por meio de hábitos saudáveis e a prática de esportes.

Os termos que configuraram as hipóteses do núcleo periférico do grupo entre 40 e 50 anos foram na sua grande maioria positivos, e remetem também tanto a aspectos físicos quanto aos cuidados de saúde. O grupo de mulheres acima de 60 anos, diferentemente dos outros dois grupos, não evocou nenhum vocábulo relacionado com o rejuvenescimento físico. Infere-se que, para essas mulheres, o gradiente de centralidade que explica o rejuvenescimento não se define a partir de uma pele lisa apenas, e sim de cuidados corporais que vão desde a hidroginástica, alimentação, saúde psicológica, etc. (quadro 6).

Nos três grupos há termos referentes ao alto custo dos tratamentos para rejuvenescer, o que mostra que todas as gerações estão cientes do valor financeiro de que se deve dispor para ter uma aparência mais jovem.

Tanto no grupo entre 25 e 35 anos, quanto no grupo que se encontrava acima de 60 anos, foram evocadas palavras nas hipóteses de núcleo periférico associadas à impossibilidade de rejuvenescer. Isso significa que, mesmo que haja um desejo de aparentar ser mais jovem, essas mulheres sabem que o início do envelhecimento é o nascimento e que um dia todos envelhecerão.

Consta no núcleo periférico distante do grupo acima de 60 anos uma palavra merecedora de ênfase: "perigoso". Isso demonstra que essas mulheres participantes da pesquisa são informadas sobre os riscos que os métodos e técnicas que promovem o rejuvenescer podem oferecer. Percebe-se então a importância da informação que, segundo Moscovici ${ }^{13}$ (1978), diz respeito a todo conhecimento que um grupo possui em relação ao objeto da representação social, para a formação de uma crítica em re- 
lação ao uso indiscriminado de métodos de rejuvenescimento.

\section{CONSIDERAÇÕES FINAIS}

Segundo Nascimento-Schulze ${ }^{15}$ \& Camargo $^{12}$ (2000, p. 296), a análise de evocações consiste numa espécie de análise lexicográfica, na qual a palavra funciona como um índice empírico que corresponde ao indicador elemento de uma representação social. Como foi descrito no início do capítulo sobre método, o estudo permitiu levantar os possíveis elementos centrais das representações sociais sobre envelhecimento e rejuvenescimento. Estas hipóteses centrais foram feitas tendo como base um único critério: saliência.

A pesquisa permite concluir que, ao redor do tema "envelhecimento", houve elementos que permitiram hipotetizar que existe consenso entre os três grupos em relação a alguns conteúdos. De um lado, esses conteúdos estavam ligados a imagens cristalizadas culturalmente em função de sabedoria, experiência e maturidade. De outro, houve elementos de conotação negativa, representados fundamentalmente pelas palavras "medo" e "solidão". Elementos que não foram consensuados entre os grupos apareceram na palavra "tristeza", que foi evocada no grupo de mulheres entre 40 e 50 anos, e nas evocações de conotação positiva "paz", "tranqüilidade" e "amor", do grupo de mulheres acima de 60 anos.

Quando se trata de assuntos ligados ao tema "rejuvenescimento", diferente das evo- cações sobre o assunto envelhecimento, nos elementos evocados entre os três grupos houve um consenso no qual predominaram dois aspectos. Um aspecto positivo ligado à alegria, bem-estar e felicidade, e um aspecto negativo, identificado a partir das evocações "dúvida" e "insegurança". Outros aspectos apontaram para algumas especificidades em cada um dos grupos: no grupo de mulheres acima de 60 anos, a evocação dos termos "caminhada / exercícios físicos", que podem ser avaliados dentro de uma dimensão funcional $\left(\mathrm{Sá}^{20}, 1996\right)$.

Parece haver consenso de que, para atingir um certo rejuvenescimento, um dos métodos que devem ser utilizados são os preventivos e, nessa prevenção, o exercício físico ocupa lugar essencial. Nos exercícios físicos parecem estar alternativas saudáveis para o rejuvenescimento. Lamentavelmente, essas alternativas não apareceram na centralidade dos outros grupos.

\section{NOTAS}

a Mestre em Psicologia Social pela Universidade Federal de Santa Catarina. Doutora em Filosofia da Saúde pela Universidade Federal de Santa Catarina. Vínculo Institucional Atual: Universidade Presbiteriana Mackenzie. São Paulo. Brasil

b Bacharel em Psicologia pela Universidade Presbiteriana Mackenzie. São Paulo. Brasil 


\section{REFERÊNCIAS}

1. Abric JC. A abordagem estrutural das representações sociais. In: Moreira ASP. Oliveira DC, organizadores. Estudos interdisciplinares de representação social. Goiânia: AB Editora; 1998. p. 27-38.

2. Baltes P. Theoretical propositios of life-span developmental psychology: on the dynamics betwen growth and decline. Developmental Psychology 1987; 5: 611-26.

3. Barbosa FT, et al . Thoracic epidural anesthesia for mammaplasty in myasthenia gravis patient: case report. Rev Bras Anestesiol 2005; 55 (3): Available from: URL: http://www.scielo.br/ scielo.php?script $=$ sci_arttext\&pid $=\mathrm{S} 0034$ $70942005000300013 \& \operatorname{lng}=$ en\&nrm $=$ iso.

4. Concio PC, Rolando Z, organizadores. Rejuvenescimento facial. São Paulo: Medisa; 1977.

5. Doise W. Atitudes e representações sociais. In: Jodelet $\mathrm{D}$, organizador. As representações sociais. Rio de Janeiro: EDUERJ; 2001. p.187-204.

6. Durkheim E. As regras do método sociológico. São Paulo: Companhia Editora Nacional, 1963.

7. Flament C. Estrutura e dinâmica das representações sociais. In: Jodelet D, organizador. As representações sociais. Rio de Janeiro: EDUERJ; 2001. p. 173-86.

8. http//www.ibge.com.br/home/ presidencia/noticias/0404.sintese.shtm

9. http//www.cirurgiaplastica.com.br

10. Jodelet D, organizador. As representações sociais. Rio de Janeiro: EDUERJ; 2001.

11. Jorge MM. A mulher e o envelhecimento na contemporaneidade. Revista de Psicologia 1999; 2(9): 14-23.
12. Morin E. Cultura de massas no século XX. Rio de Janeiro: Forense Universitário; 2000. v.1. Neurose.

13. Moscovici S. A representação social da Psicanálise. Rio de Janeiro: Zahar; 1978.

14. __. On social representations. In: Forgas PJ, organizador. Social Cognition. London: Wales South University; 1981. p.181-291.

15. Nascimento-Schulze C, Camargo BV. Psicologia Social, representações sociais e métodos. Temas em Psicologia 2000; 8(3): 287-99.

16. Neugarten EA, Hagestad GD. Age and life course. In Binstock R, Shanas E, editors. Handbook of aging and the social sciences. New York: Van Nostrnd-Reinhold, 1976.

17. Nociti JR, et al. Dexmedetomidine/ propofol association for plastic surgery sedation during local anesthesia. Rev Bras Anestesiol 2003; 53 (2): Available from: URL: http://www.scielo.br/ scielo.php?script $=$ sci_arttext\&pid $=$ S003470942003000200007\&lng $=\mathrm{en} \& \mathrm{nrm}=$ iso.

18. Revista COREN-SP 2003 jan./ fev. ; 43.

19. Revista Playboy 2003 abril; 333 .

20. Sá CP. Núcleo central de representações sociais . Petrópolis: Vozes; 1996.

21. Santos MFS, Belo I. Diferentes modelos de velhice. Revista Semestral da Faculdade de Psicologia 2000; 31(2): 31-48.

22. Schabbel C. Mediação escolar de pares. São Paulo: Willis Harman House (WHH); 2002.

23. Stuart-Hamilton I. A Psicologia do envelhecimento: uma introdução. 3. ed. Porto Alegre: Artmed, 2002.

24. Teixeira MCTV, Domingues C, Prado GA, Maeda M, Fioravanti, Braite R, Paves T. Espelho, espelho meu: existe alguém mais jovem do que eu?. Revista Psychologica 2006; 42: 231-50. 
25. Teixeira MCTV, Settembre FM, Leal SB. Envelhecimento, rejuvenescimento e ciência e a tecnologia ao serviço do rejuvenescimento: um levantamento de conteúdos de representações sociais em mulheres de três faixas etárias diferentes. No prelo na Revista "The Spanish Journal of Psychology".
26. Vergès P.L'èvocation de l'argent: une mèthode pour la definition du noyau central d' une reprèsentation. Bulletin de Psychologie 1992; 45 (405): 203-09.

Recebido para publicação em: 06/12/2005 Versão final apresentada em: 29/11/2006 Aceito em: 11/12/2006 
72 Rev. Bras. Geriatr. Gerontol., 2007; 10(1):49-72 